\title{
Model for the Prescription of the Appropriate Inhibition Technique for Hydrates in Natural Gas Streams
}

\author{
Anyadiegwu Charley Iyke C \\ Department of Petroleum Engineering, \\ Federal University of Technology, Owerri. \\ Ohia N.P. \\ Department of Petroleum Engineering, \\ Federal University of Technology, Owerri. \\ Muonagor Chukwuemeka M. \\ Institute of Petroleum Studies, Port Harcourt, \\ in affiliation with Institut Francais du Petrole (IFP), France.
}

\begin{abstract}
Appropriate inhibition technique for hydrates in natural gas streams was presented. The data for three natural gas streams were obtained for the study. There is possibility of hydrate formation in the natural gas streams. Based on their variable flow rates and water contents, they had different appropriate inhibition techniques. The computer model showed that the appropriate inhibition technique for gas stream $A$ is Heating the Gas Stream to High Temperatures; that for gas stream B is Passing the Gas Stream across Methanol or Ethylene Glycol to absorb the Water in the Gas; For gas stream B, PVTP, a reservoir engineering program was applied to determine the minimum weight $\%$ of glycol required to protect the gas up to 5000 psig at $50^{\circ} \mathrm{Fas} 29.8062$ and that of methanol as 19.3878. From the evaluations, it is seen that less methanol is required to protect the gas from forming hydrate at low temperatures than glycol. For gas stream $\mathrm{C}$, the model prescribed Passing the Gas Stream through a Glycol Dehydrator Column. The amount of water to be removed was estimated as $2.98 \mathrm{lb}_{\mathrm{m}} / \mathrm{hr}$ and the required glycol circulation rate as $0.075 \mathrm{gal} / \mathrm{hr}$.
\end{abstract}

Key Words: Natural gas stream, flow rate, hydrate, water content, inhibition, prescription, glycol, temperature, dehydrator, methanol.

\section{INTRODUCTION}

Gas hydrates are stable only under specific pressure-temperature conditions. Under the appropriate pressure, they can exist at temperatures significantly above the freezing point of water. The maximum temperature at which gas hydrate can exist depends on pressure and gas composition. For example, methane plus water at 600 psia forms hydrate at $41^{\circ} \mathrm{F}$, while at the same pressure, methane $+1 \%$ propane forms a gas hydrate at $49^{0} \mathrm{~F}$. Hydrate stability can also be influenced by other factors, such as salinity (Edmonds et al., 1996).

According to Calvert, (2010), Gas hydrates form at temperatures above those of pure ice formation, which is an interesting point for discussion. Let us see if qualitative considerations can lead to an understanding of this. When ice forms from liquid water, the decrease in entropy is relatively small $(0.292 \mathrm{Btu} / \mathrm{lb}-\mathrm{R})$ because water itself is fairly ordered, so the energy made available by the more efficient hydrogen bonding in ice relative to water is enough, when dissipated into the surroundings, to make the net entropy change positive, as it must be for a spontaneous process. At $4^{\circ} \mathrm{C}$, methane forms hydrates above 551 psia. At $0^{\circ} \mathrm{C}$, the required pressure falls to 370 psia. When a gas hydrate is formed, there is a considerable reduction in entropy because the gas is, in effect, condensed into a small volume. This is offset by the availability of the kinetic energy of the gas molecules, and a contribution from the van der Waals attraction between host and guest, which can be turned into entropy in the surroundings (exothermic reaction). The net result, as observed, is that the solid can be formed at temperatures above those of the formation of pure ice. It is reasonable that it is more difficult for small molecules, such as $\mathrm{N}_{2}$ and $\mathrm{CH}_{4}$, to form hydrates because their van der Waals interaction is weaker than for larger or more polarizable molecules such as $\mathrm{H}_{2} \mathrm{~S}$ or $\mathrm{C}_{2} \mathrm{H}_{6}$.

Methane hydrates are sensitive sediments. They can rapidly dissociate with an increase in temperature or a decrease in pressure. This dissociation produces free methane and water. The conversion of a solid sediment into liquids and gases will create a loss of support and shear strength. These can cause submarine slumping, landslides or subsidence that can damage production equipment and pipelines (United States Department of Energy, 2011).

Methane is a powerful greenhouse gas. Warmer Arctic temperatures could result in gradual melting of gas hydrates below permafrost. Warming oceans could cause gradual melting of gas hydrates near the sedimentwater interface. Although many news reports have presented this as a potential catastrophe, USGS research has 
determined that gas hydrates are currently contributing to total atmospheric methane and that a catastrophic melting of unstable hydrate deposits is unlikely to send large amounts of methane into the atmosphere (Ruppel, 2012).

According to Sira et al., (1990), Gas hydrates are clathrate compounds in which each water molecule forms hydrogen bonds with its four nearest water molecules to build a solid crystalline lattice structure that encages gas molecules in its interstitial cavities. Hammerschmidt, (1934), determined that these solid gas hydrates form during transportation of natural gas and cause severe problems of blockages in pipelines. Since then, several methods of prevention of formation of gas hydrates were developed. The most commonly employed industrial methods include: removal of moisture content of natural gas by dew point lowering method, heating of a section containing hydrate plug to raise its temperature above hydrate dissociation temperature, depressurization of a hydrate plug simultaneously from both ends at a slow rate to a pressure below hydrate dissociation pressure, and injection of chemicals which act as hydrate inhibitors into the gas flow stream.

The term "hydrate inhibitor" is used for those chemicals which have ability to lower hydrate formation temperature (or shift hydrate equilibria). These chemicals include: methanol, glycols, ammonia, salts such as chlorides of sodium, potassium, calcium and magnesium. Several studies have been reported in literatures which provide experimental data on effect of inhibitor concentration on the thermodynamic phase equilibria of gas hydrates. Makogon (1981) and Sloan et al, (1990) provided good review of these studies and a discussion on effectiveness and screening of these inhibitors for hydrate prevention. In general, the degree of inhibition is a function of the type of inhibitor, inhibitor concentration, pressure and composition of hydrate forming gas.

Recently published field experiments showed that hydrate blockage could form more readily in under-inhibited systems than in systems completely without inhibitor. On the basis of this experience, under-inhibited systems appear to be more likely to cause hydrate problems than systems completely without inhibitor. Consequently, the amount of the inhibitor in the pipeline must be maintained at such a level that hydrate formation will not be encountered (Austvik et al., 1995).

Yousif, (1996), Methanol injection has been used effectively to keep hydrates from forming as well as to release hydrate plugs restricting or stopping gas flow. Methanol is used as a means of preventing hydrate plugging or freezing in offshore hydrate control operations.

Inhibition experiments have been conducted using the methanol to inhibit hydrate formation in a pipeline. As the result, methanol had lower formation temperature than pure water but it was used as promoter to enhance the rate and amount of hydrate formation after the onset of hydrate formation.

These works can provide the predicting techniques of the hydrate plugging phenomena and hydrate control techniques by the inhibitor in the sub-sea pipeline system as well as flowlines of natural gas production system. Specifically, the results of this study can be applied to the selection of the prevention criteria and method of hydrate formation (Anderson et al., 1986).

\section{HYDRATE MITIGATION AND REMEDIATION}

The formation of hydrates requires four essential elements to occur: a supply of hydrate forming guest molecules, a supply of water and a combination of high pressure and/or low temperatures. Strategies for hydrate remediation and mitigation often modify one of these elements to destabilize the hydrate and thus remove the problem.

Hydrates can also be prevented by the injection of chemical inhibitors which seek to modify the chemistry of hydrate formation such that the system is operated outside the hydrate envelope. There are various methods used in hydrate prevention:

* Temperature control

* Pressure control

* Water removal

* Insulation

* Thermodynamic inhibitors

* Low dosage hydrate inhibitors

Hydrate prevention using these techniques are reviewed, considering their application to deep water gas production systems for normal operation shutdown and restart. This review includes evaluation of the prevention techniques, considering technical issues associated with their application, level of protection, limitation, risk and cost of impact.

\section{METHODOLOGY \\ 3.1 Prescription of the Appropriate Inhibition Technique for Hydrate Formation}

This involves the use of computer program developed with Microsoft Visual Basic Program for prescribing the appropriate inhibition or prevention technique for hydrates.

The properties of the gas sample required for this evaluation are flow rate of the gas and the measured water content of the gas. A sample of the Microsoft Visual Basic Program for prescribing the appropriate inhibition or prevention technique for hydrates is as shown in Fig 3.1. 


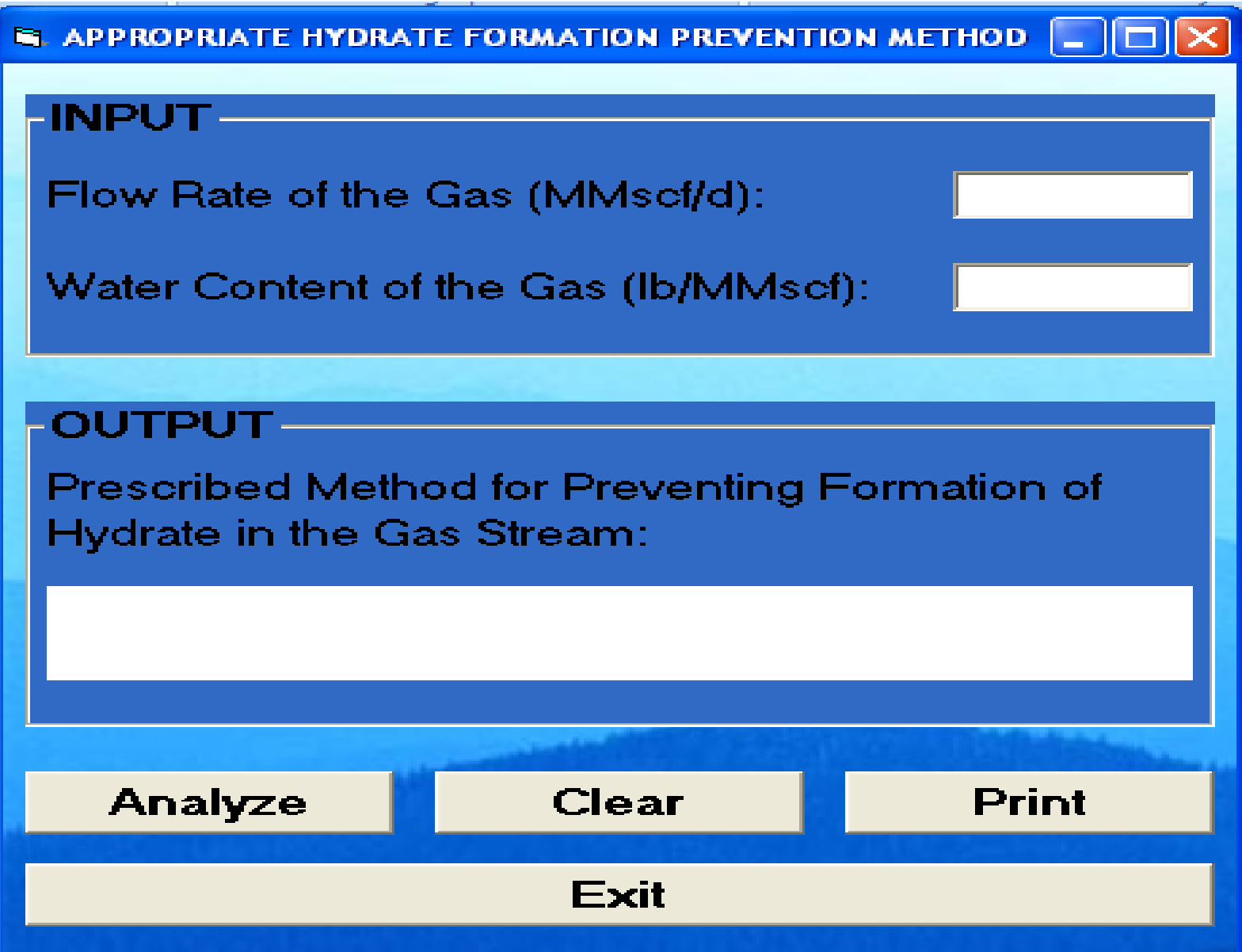

Fig 3.1: Microsoft Visual Basic Program for Prescribing the Appropriate Inhibition or Prevention Technique for Hydrate Formation

\subsection{Procedure for Evaluation of a Gas Sample}

The only step is to perform analysis using the Computer Program shown in Fig 3.1 for the prescribed appropriate inhibition or prevention technique; ie whether the prevention technique required according to the computer program is Heating, Glycol Injection or Dehydration.

If the result of the analysis is Heating then heat is to be applied to the gas stream to bring it up to temperatures above which hydrate cannot form.

If the result is Glycol Injection, evaluate the weight $\%$ and mole $\%$ of the required glycol.

If the result is Dehydration, evaluate the amount of water in the gas to be removed to meet specification requirement and the required glycol circulation rate in the dehydration system.

In the case of the gas stream where hydrate has already formed within the orifice and the hydrate thickness has been obtained, then determine the effect of hydrate thickness on the gas flow rate through the orifice.

\section{RESULTS}

Data were collected for gas samples on four different natural gas streams flowing at different flow rates. The data are presented for the four natural gas streams in Tables 4.1, 4.2, 4.3 and 4.6.

\subsection{Case 1: Natural Gas Stream A}

Table 4.1: Data for Natural Gas Stream A

\begin{tabular}{|l|l|}
\hline Gas Temperature, ${ }^{0} \mathrm{~F}$ & 30 \\
\hline Gas Pressure, psig & 1600 \\
\hline Gas Specific Gravity & 0.45 \\
\hline Gas Flow Rate, MMscf/d & 0.66 \\
\hline Water Content of the Gas, lb/MMscf & 11 \\
\hline
\end{tabular}

Fig 3.1 is applied to evaluate the prescribed appropriate prevention technique for hydrate formation in the natural gas stream. This is as shown in Fig 4.1. 


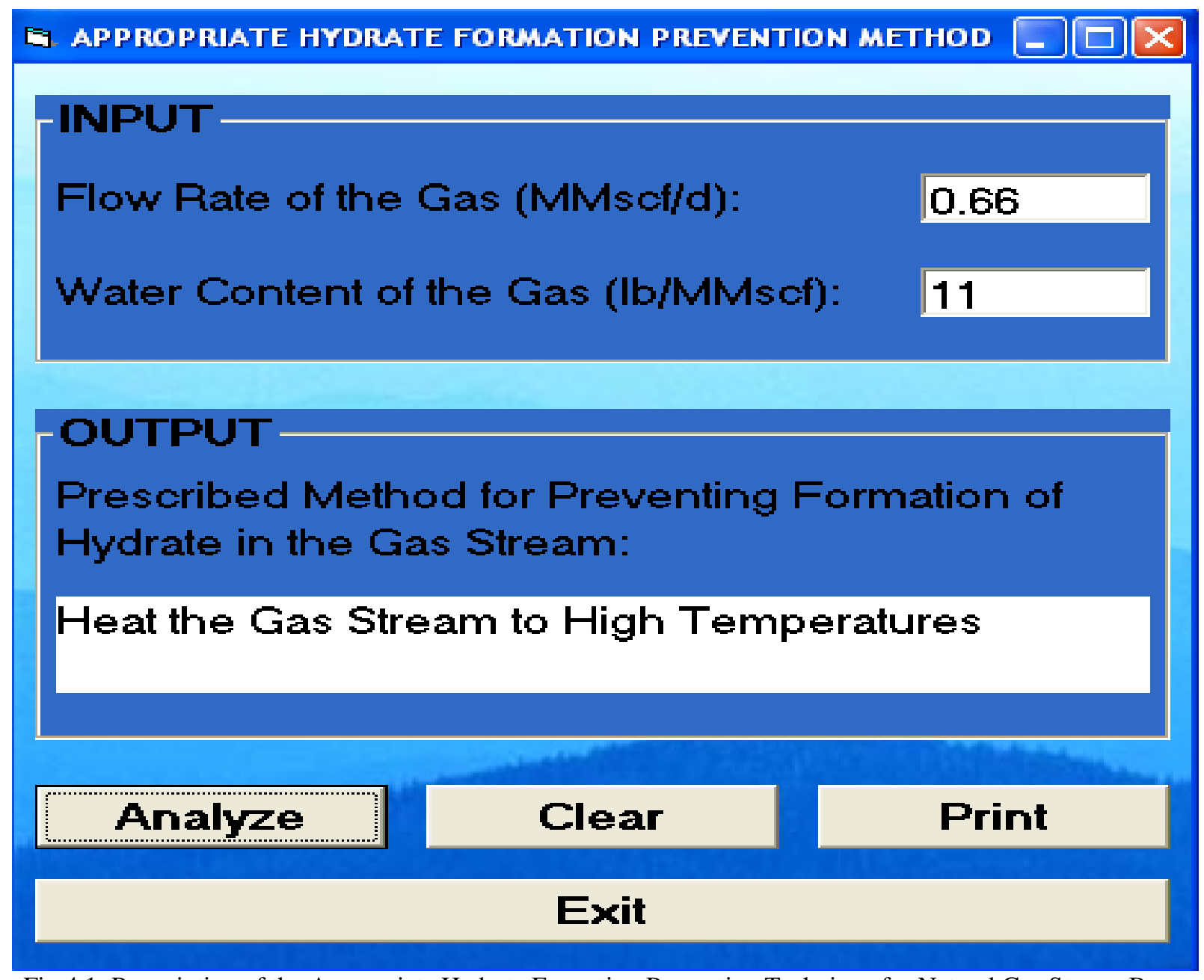

Fig 4.1: Prescription of the Appropriate Hydrate Formation Prevention Technique for Natural Gas Stream B.

A Reservoir Engineering Program, PVTP was applied to produce a chart of the Hydrate Formation Pressures of Natural Gas Stream A at various Gas Temperatures and the plot of Hydrate Formation Pressure against Gas Temperature is shown in Fig 4.2 below. 


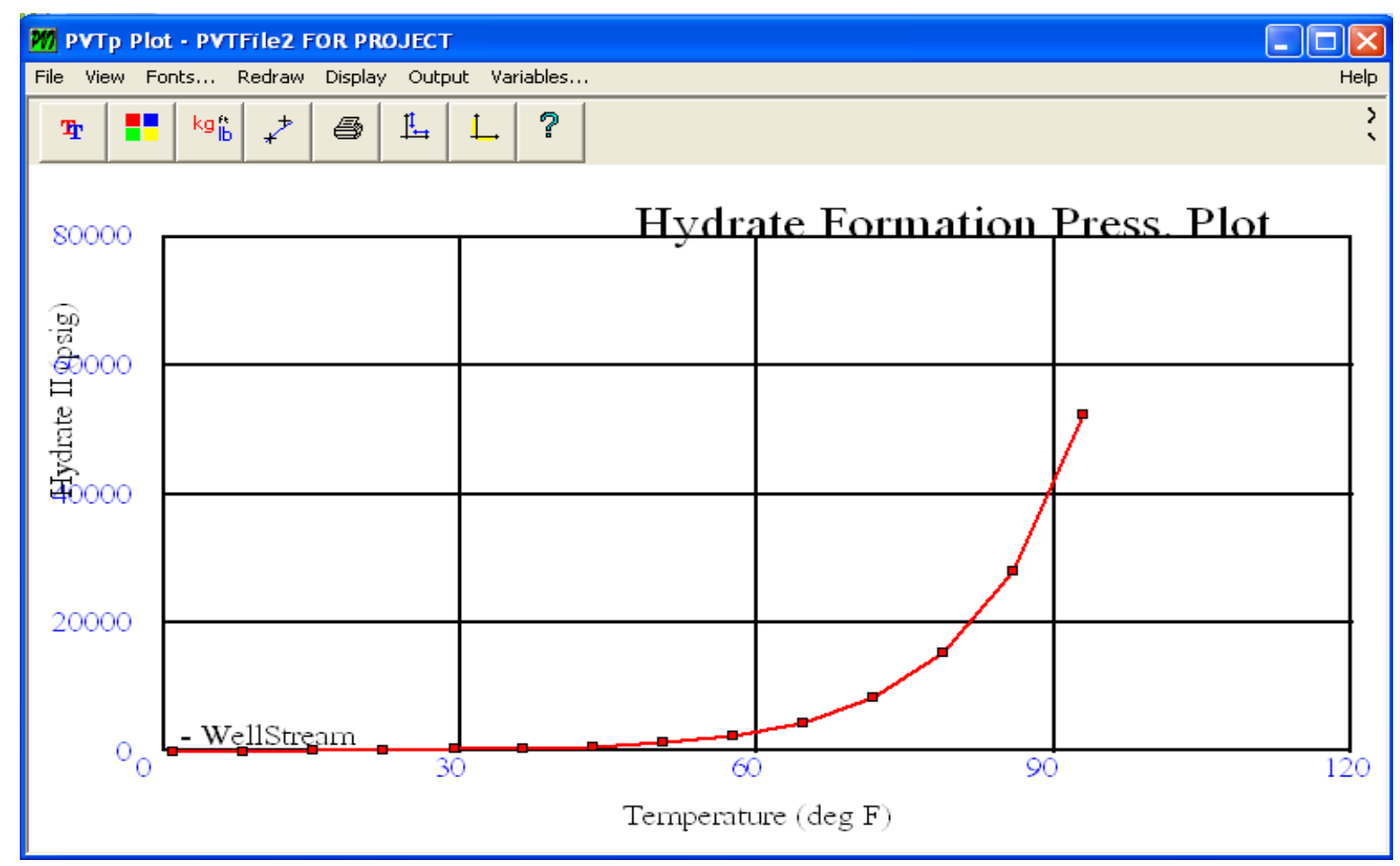

Fig 4.2: Plot of Hydrate Formation Pressure against Gas Temperature for Natural Gas Stream A.

4.2 Case 2: Natural Gas Stream B

Table 4.2: Data for Natural Gas Stream B

\begin{tabular}{|l|l|}
\hline Gas Temperature, ${ }^{0} \mathrm{~F}$ & 50 \\
\hline Gas Pressure, psig & 1500 \\
\hline Gas Specific Gravity & 0.4 \\
\hline Gas Flow Rate, MMscf/d & 0.70 \\
\hline Water Content of the Gas, lb/MMscf & 23.5 \\
\hline
\end{tabular}

Fig 3.1 is applied to evaluate the prescribed appropriate prevention technique for hydrate formation in the natural gas stream. This is as shown in Fig 4.3. 


\section{-INPUT -}

Flow Rate of the Gas (MMscf/d):

0.70

Water Content of the Gas (Ib/MMscf):

23.5

\section{- OUTPUT}

Prescribed Method for Preventing Formation of Hydrate in the Gas Stream:

\section{Pass the Gas Stream across Methanol or Ethylene Glycol to absorb the Water in the Gas}

\section{Analyze}

\section{Clear}

\section{Print}

\section{Exit}

Fig 4.3: Prescription of the Appropriate Hydrate Formation Prevention Technique for Natural Gas Stream C.

From Fig 4.3, the prescribed prevention technique is passing the gas stream across glycol or methanol. A reservoir engineering program, PVTP is used to determine the minimum ethylene glycol concentration in weight $\%$ and mole $\%$ required to inhibit the hydrate formation and protect the gas stream up to 5000 psig at the same temperature as shown in Fig 4.4 


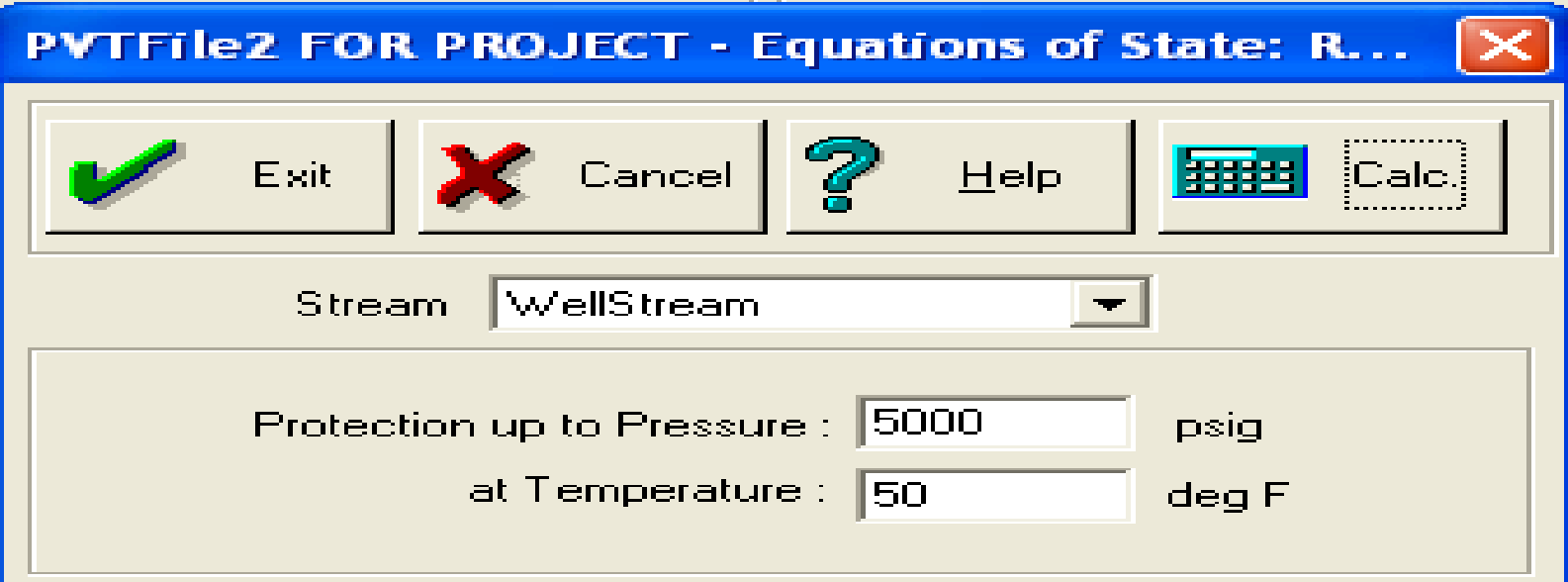

Inhibitor Eth. Gilycoal

Fiestalts

Mirimum I rahibitar Conc:entration :

29.9062 weight $\%$ mole 2

Fig 4.4: Minimum Ethylene Glycol required for protecting the gas from Hydrate Formation up to 5000 psig at the same Temperature for Natural Gas Stream B.

Using Fig 4.4, the minimum glycol concentration in weight \% required to protect the gas stream from hydrate formation up to $5000 \mathrm{psig}$ at various gas temperatures were evaluated and presented in Table 4.3 which was used to generate plot of Minimum Glycol Concentration in weight \% against Gas Temperature as shown in Fig 4.5.

Table 4.3: Minimum Ethylene Glycol Concentration at various Gas Temperatures

\begin{tabular}{|c|c|}
\hline Gas Temperature, ${ }^{0} \mathrm{~F}$ & Minimum Glycol Conc, wt \% \\
\hline 10 & 62.57 \\
\hline 20 & 56.69 \\
\hline 30 & 49.56 \\
\hline 40 & 40.98 \\
\hline 50 & 29.81 \\
\hline 60 & 15.78 \\
\hline 70 & 0.97 \\
\hline 80 & 0.97 \\
\hline 90 & 0.97 \\
\hline 100 & 0.97 \\
\hline
\end{tabular}




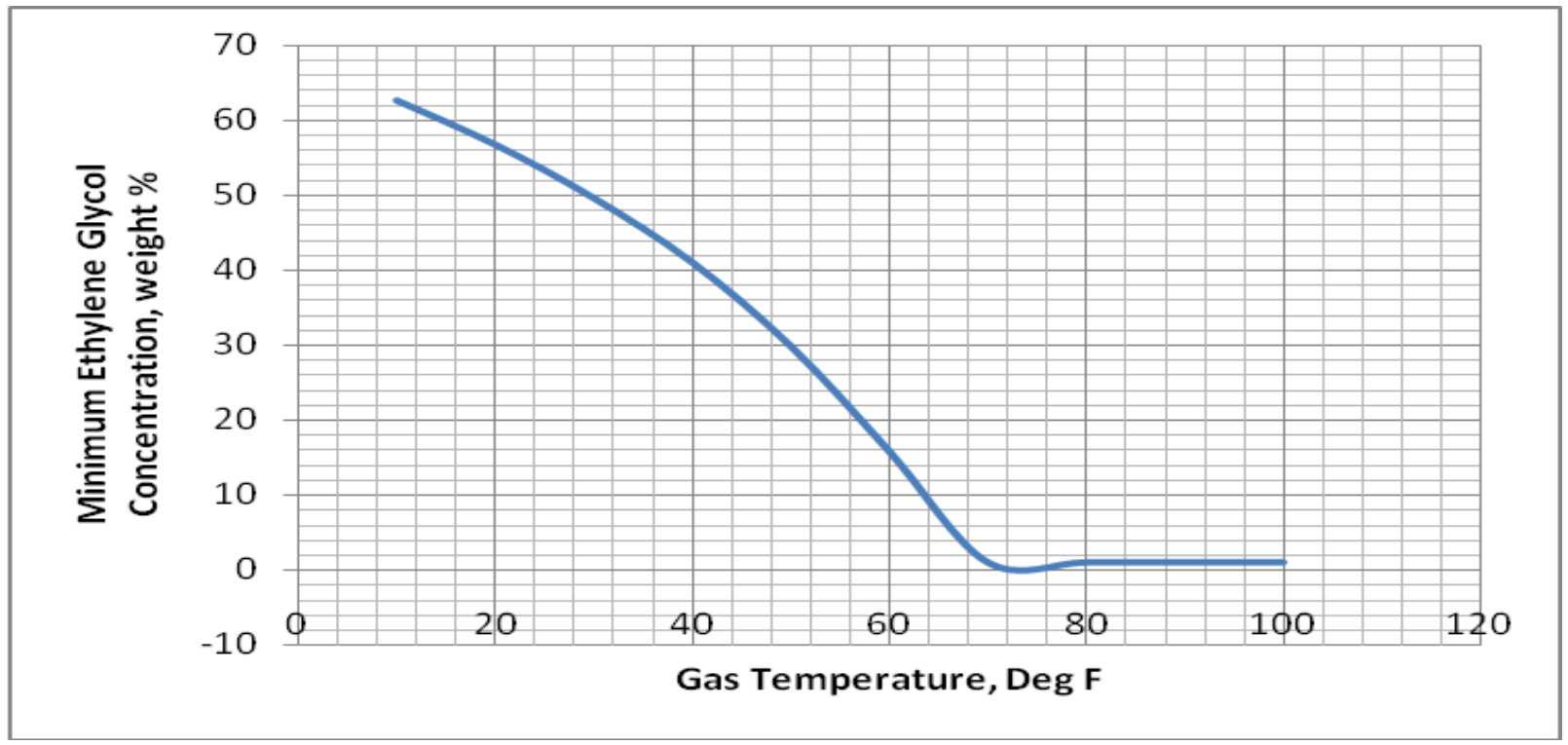

Fig 4.5: Minimum Glycol Concentration at various Gas Temperatures

The minimum methanol concentration in weight $\%$ and mole $\%$ required to inhibit the hydrate formation and protect the gas stream up to 5000 psig at the same temperature as shown in Fig 4.6.

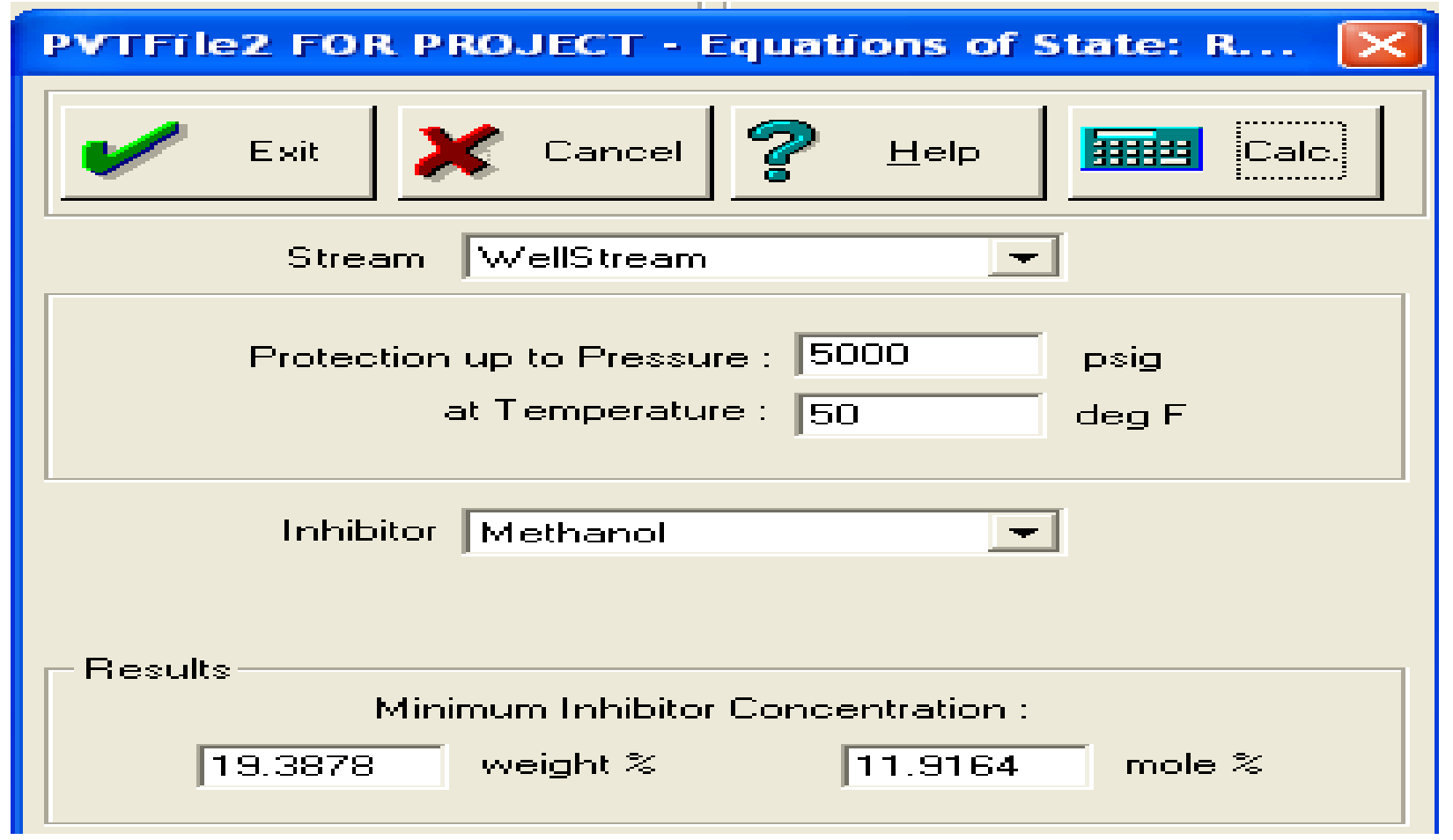

Fig 4.6: Minimum Methanol required for protecting the gas from Hydrate Formation up to 5000 psig at the same Temperature for Natural Gas Stream B.

Using Fig 4.6, the minimum methanol concentration in weight \% required to protect the gas stream from hydrate formation up to $5000 \mathrm{psig}$ at various gas temperatures is presented in Table 4.4 and used to generate plot of Minimum Methanol Concentration in weight \% against Gas Temperature as shown in Fig 4.7. 
Table 4.4: Minimum Methanol Concentration at various Gas Temperatures

\begin{tabular}{|c|c|}
\hline Gas Temperature, ${ }^{0} \mathrm{~F}$ & Minimum Methanol Conc, wt \% \\
\hline 10 & 47.2 \\
\hline 20 & 41.3 \\
\hline 30 & 34.76 \\
\hline 40 & 27.48 \\
\hline 50 & 19.39 \\
\hline 60 & 10.41 \\
\hline 70 & 2.26 \\
\hline 80 & 2.26 \\
\hline 90 & 2.26 \\
\hline 100 & 2.26 \\
\hline
\end{tabular}

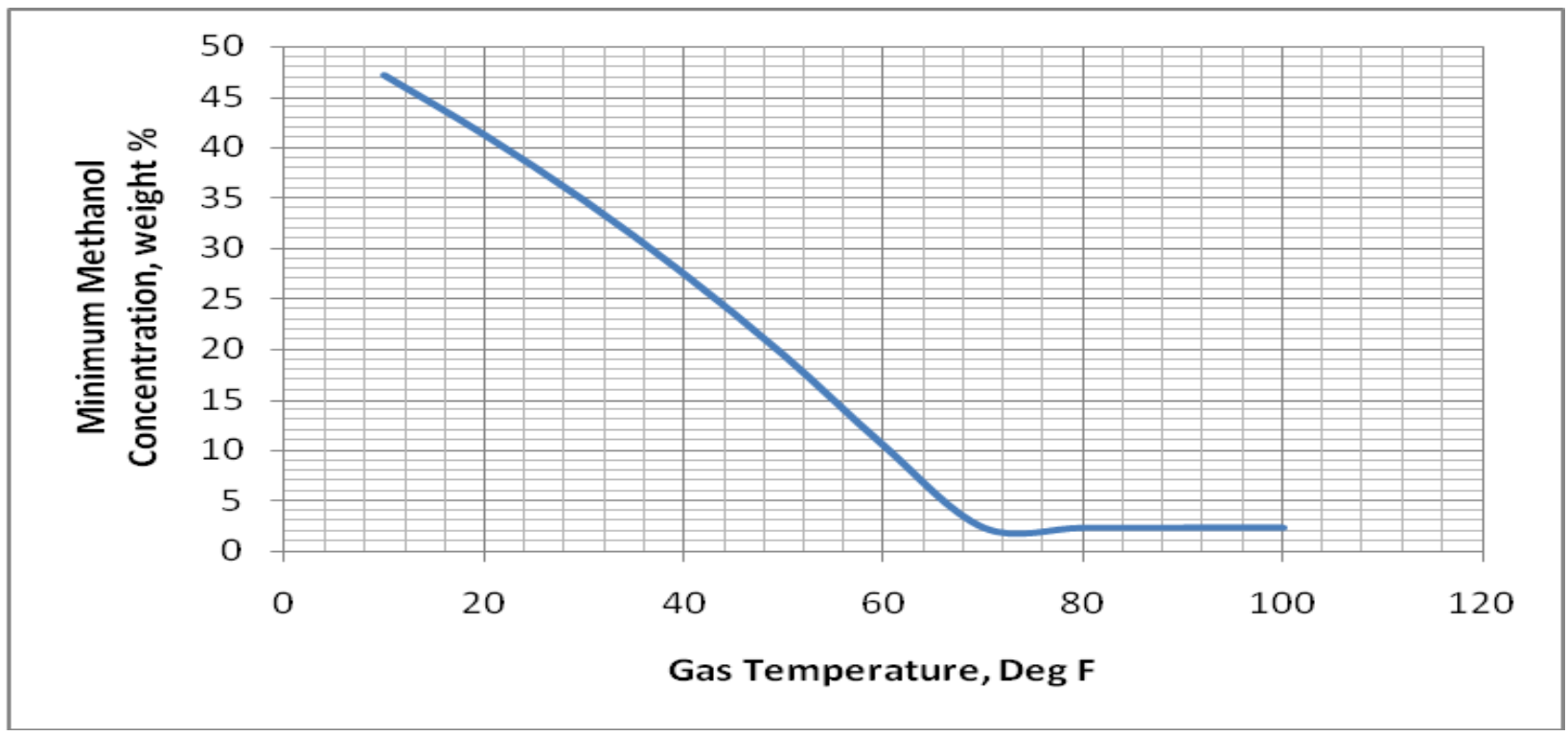

Fig 4.7: Minimum Methanol Concentration at various Gas Temperatures

4.3 Case 3: Natural Gas Stream C

Table 4.5: Data for Natural Gas Stream C

\begin{tabular}{|l|l|}
\hline Gas Temperature, ${ }^{0} \mathrm{~F}$ & 55 \\
\hline Gas Pressure, psig & 1430 \\
\hline Gas Specific Gravity & 0.55 \\
\hline Gas Flow Rate, MMscf/d & 2 \\
\hline Water Content of the Gas, lb/MMscf & 36 \\
\hline
\end{tabular}

Fig 3.1 is applied to evaluate the prescribed appropriate prevention technique for hydrate formation in the natural gas stream. This is as shown in Fig 4.8. 
G APPROPRIATE HYDRATE FORMATION PREVENTION METHOD $\square \square \square$

INPUT -

Flow Rate of the Gas (MMscf/d):

2

Water Content of the Gas (Ib/MMscf):

\section{OUTPUT}

Prescribed Method for Preventing Formation of Hydrate in the Gas Stream:

\section{Pass the Gas Stream through a Glycol Dehydrator Column}

Analyze

Clear

Print

\section{Exit}

Fig 4.8: Prescription of the Appropriate Hydrate Formation Prevention Technique for Natural Gas Stream C.

From Fig 4.8, the prescribed prevention technique is passing the gas stream through glycol dehydrator column. The Amount of Water in $\mathrm{lb}_{\mathrm{m}} / \mathrm{hr}$ to be removed from the gas to meet specification is estimated using Eq 4.1 as: Amount of water to be removed $=\left(\mathrm{C}_{\mathrm{wi}}-\mathrm{C}_{\mathrm{wo}}\right) \mathrm{q} / 24$

Where $\mathrm{C}_{\mathrm{wi}}=$ Water content of inlet gas, $\mathrm{lb}_{\mathrm{m}} \mathrm{H}_{2} \mathrm{O} / \mathrm{MMscf}$

$\mathrm{C}_{\mathrm{wo}}=$ Water content of outlet gas to meet specification, $0.3 \mathrm{lb}_{\mathrm{m}} \mathrm{H}_{2} \mathrm{O} / \mathrm{MMscf}$

$\mathrm{q}=$ Gas flow rate, $\mathrm{MMscf} / \mathrm{d}$

From eq 4.1, Amount of water removed $=(36-0.3) * 2 / 24=2.98 \mathrm{lb} / \mathrm{hr}$

The Glycol Circulation Rate in gal/hr is determined using Eq 4.2 as:

$\mathrm{q}_{\mathrm{G}}=(\mathrm{GWR}) \mathrm{C}_{\mathrm{wi}} \mathrm{q} / 24$

where GWR = Glycol to Water ratio, 3 gal.TEG/lb $\mathrm{m}_{\mathrm{m}} \mathrm{H}_{2} \mathrm{O}$

From eq 4.2, Glycol Circulation Rate $=3 * 0.3 * 2 / 24=0.075 \mathrm{gal} / \mathrm{hr}$

Using eq 4.2, the Glycol Circulation Rate at various Water Content of the inlet gas is computed and presented in

Table 4.6 and used to generate plot of Glycol Circulation Rate against Water Content as shown in Fig 4.9.

Table 4.6: Glycol Circulation Rate at various Water Content

\begin{tabular}{|c|c|}
\hline Water Content, lb/MMscf & Glycol Circulation Rate, gal/hr \\
\hline 0.3 & 0.075 \\
\hline 3.3 & 0.825 \\
\hline 13 & 3.25 \\
\hline 23 & 5.75 \\
\hline 33 & 8.25 \\
\hline 43 & 10.75 \\
\hline 53 & 13.25 \\
\hline 63 & 15.75 \\
\hline
\end{tabular}




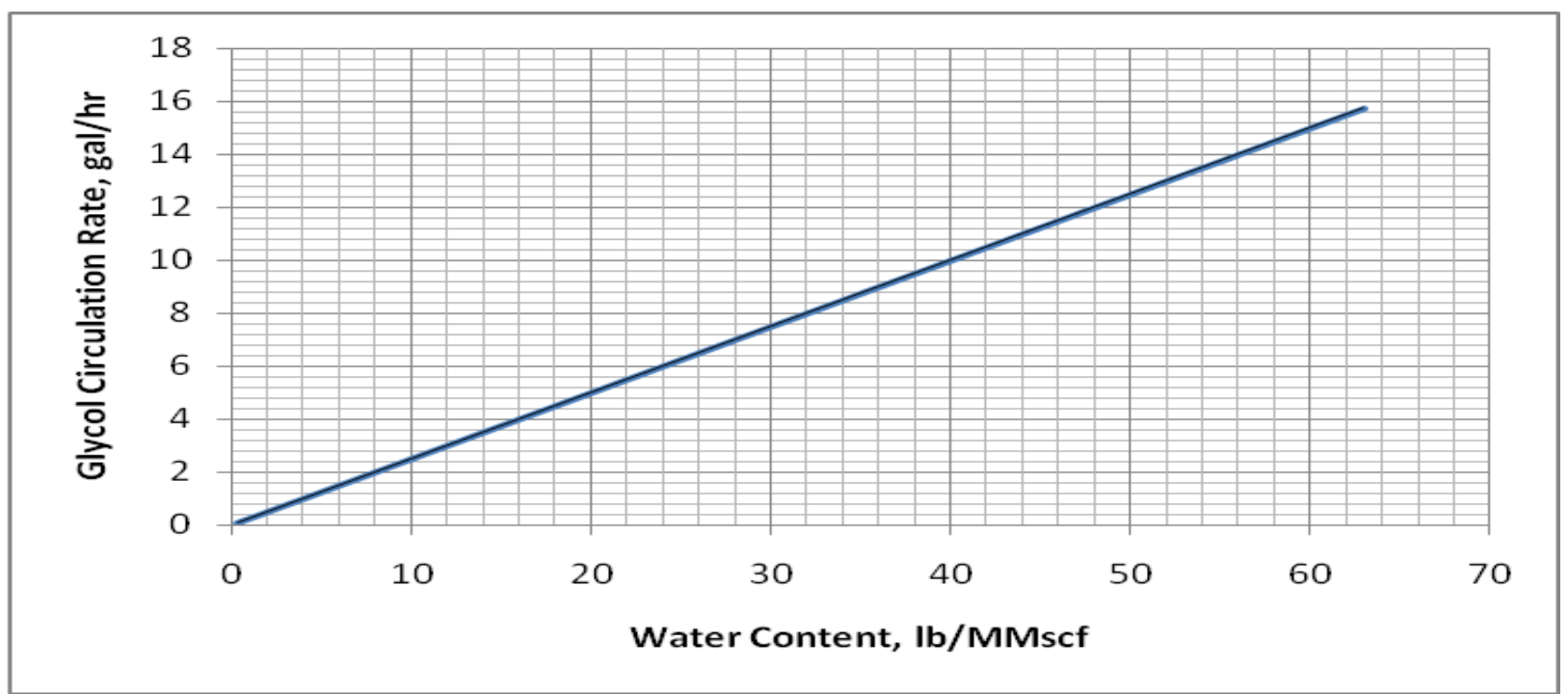

Fig 4.9: Glycol Circulation Rate at various Water Content

\section{CONCLUSION}

Hydrate formation analyses on gas streams A to $\mathrm{C}$ were carried out in this research work. From the evaluations conducted using the equations, computer models and charts, the following conclusions may be drawn:

1. At low pressures and high temperatures, hydrate is less likely to form in natural gas stream than at low temperatures and high pressures. If a gas sample is evaluated to be susceptible to hydrate formation then heating the gas to high temperatures can cushion the problem of hydrate formation.

2. When the water content of the gas sample is not too high and the flow rate is high then heating the gas to high temperatures may not likely be the long-lasting inhibition technique to the formation of hydrate in the gas stream. It is then advisable to pass the gas stream through glycol/methanol or even send the gas into a glycol dehydrator column which is the ideal inhibition technique for gas streams with high water content and high flow rate.

3. It is less material-utilizing to use methanol when protecting the gas from forming hydrate at low temperatures than to use glycol since less methanol is required to protect the gas from hydrate formation up to any given pressure at low temperatures.

4. From the plot of glycol circulation rate against water content of the gas it is seen that higher glycol circulation rates are needed in the dehydrator column if the gas sent into the dehydrator column has larger water content and thus the amount of water to be removed from the gas to meet specification.

\section{REFERENCES}

[1] Anderson, F. E. and Prausnitz, J. M., (1986): Inhibition of Gas Hydrate by Methanol. J. AIChE, 32:1321-1333.

[2] Austvik, T., Hustvedt, E. Meland, B., Berge, L., and Lysne, D., (1995): Tommeliten Gamma Field Hydrate Experiments. Proc. of the 7 th International Conference on Multiphase Production, Cannes, France.

[3] Calvert J.B., (2010): Gas Hydrates; Created 1998 Last revised 27 May 2010

[4] Edmonds B., R.A.S. Moorwood, R. Szczepanski, (1996): Practical model for the effect of salinity on gas hydrate formation, Society of Petroleum Engineers (SPE), Stavanger, Norway, 1996, pp. 262-269.

[5] Hammerschmidt, E. G., (1934): Formation of Gas Hydrates in Natural Gas Transmission Lines. Ind. Eng. Chem., 26:851-855.

[6] Makogon Y.F., (1981): Hydrates of Natural Gas (Tulsa, OK: Penn-Well, 1981) translated by W. J. Cielewicz.

[7] Ruppel Carolyn, (2012): Gas Hydrates Offshore; Southeastern United States: Georgia Institute of Technology, NOAA Ocean Explorer website, accessed September, 2012.

[8] Sira, J.H., Patil, S.L., Kamath, V.A., (1990): Study of Hydrate Dissociation by Methanol and Glycol Injection; University of Alaska, Fairbanks; SPE Annual Technical Conference and Exhibition, 23-26 September 1990, New Orleans, Louisiana; 978-1-55563-545-9;

[9] Sloan E.D. and Bloys J.B., (2000): Hydrate Engineering, Society of Petroleum Engineers Inc., Richardson, TX, USA, 2000.

[10] United States Department of Energy, (2011): Energy Resource Potential of Methane Hydrate: An introduction to the science and energy potential of a unique resource, publication by the National Energy Technology Laboratory.

[11] Yousif, M. H., (1996): Effect of Under-Inhibition with Methanol and Ethylene Glycol on the Hydrate Control Process. Offshore Tech. Conference, $741-748$.

\section{NOMENCLATURE}

$\mathrm{BOP}=$ Blowout preventer

$\mathrm{Btu} / \mathrm{lb}-\mathrm{R}=\mathrm{British}$ thermal unit per pound per rankine

$\mathrm{CH}_{4}=$ Methane

$\mathrm{C}_{2} \mathrm{H}_{6}=$ Ethane

$\mathrm{CO}_{2}=$ Carbon dioxide 
$\mathrm{C}_{\mathrm{wi}}=$ Water content of inlet gas

$\mathrm{C}_{\mathrm{wo}}=$ Water content of outlet gas to meet specification

$\mathrm{gal} / \mathrm{hr}=$ Gallon per hour

gal.TEG/lb $\mathrm{m}_{\mathrm{m}} \mathrm{O}=$ Gallon of TEG per pound of water

$\mathrm{GWR}=$ Glycol to Water ratio

$\mathrm{H}_{2} \mathrm{~S}=$ Hydrogen sulphide

$\mathrm{lb}_{\mathrm{m}} \mathrm{H}_{2} \mathrm{O} / \mathrm{MMscf}=$ Pound of water per million standard cubic foot

$\mathrm{lb}_{\mathrm{m}} / \mathrm{hr}=$ Pound per hour

$\mathrm{lb} / \mathrm{MMscf}=$ Pound per million standard cubic foot

MMscf/d = Million standard cubic foot per day

$\mathrm{N}_{2}=$ Nitrogen

psia $=$ Pound per square inch (atmosphere)

psig $=$ Pound per square inch (gauge)

$\mathrm{q}=$ Gas flow rate

$\mathrm{q}_{\mathrm{G}}=$ Glycol circulation rate

$\mathrm{scf} / \mathrm{hr}=$ Standard cubic foot per hour

wt $\%=$ Weight percent

${ }^{0} \mathrm{C}=$ Degree celsius

${ }^{0} \mathrm{~F}=$ Degree Fahrenheit

$\%=$ Percent 